\title{
Mother's Nutritional Knowledge and Practice: A study on Slum Area of Khulna City
}

\author{
Papia Sultana and Khan Mehedi Hasan
}

\section{ABSTRACT}

\begin{abstract}
Child health and nutrition much depend on the mother's knowledge and conscious. We measure mother's nutritional knowledge and practice affecting child health and nutrition in slum areas of Khulna city in Bangladesh. We find that mothers substantially lack nutritional related knowledge, where many cannot even apply nutritional related knowledge in their daily life mainly due to economic affordability of nutrient food and other required health care services. The research also identifies factors affecting nutritional practices in slum households. The research suggests taking measures to increase nutritional knowledge of mothers and to provide nutrient foods and health care services to the disadvantaged pregnant and mothers with newborn babies.
\end{abstract}

Keywords: Child health, nutritional knowledge, nutritional practice.
Published Online: November 29,2020

ISSN: 2593-8339

DOI: $10.24018 /$ ejmed.2020.2.6.582

\section{P. Sultana}

MDS program, Economics Discipline, Khulna University, Bangladesh.

(e-mail: papiaazad ${ }^{\circledR}$ gmail.com) K. M. Hasan*

Economics Discipline, Khulna University, Bangladesh.

(e-mail: khansssku@gmail.com).

*Corresponding Author

\section{INTRODUCTION AND BACKGROUND}

\section{A. Introduction and Background of the Study}

Children represent the future of a nation for which their healthy growth and development ought to be a prime concern in all societies. Child malnutrition remains one of the most health challenges facing in Bangladesh, especially among disadvantaged group. The problem of malnutrition has a great impact on child's health, education, and mental development. A healthy and nourished child would be an asset for a country by performing better in education and become active labor force in future and hence is able to give his/her own children a better life. But unfortunately rate of malnutrition in Bangladesh is very high. According to the Save the Children, malnutrition is a broad term commonly used as an alternative to undernutrition but technically it also refers to overnutrition [16]. Undernutrition is defined as the outcome of insufficient food intake and repeated infectious diseases. It includes being underweight for one's age, too short for one's age (stunted), dangerously thin for one's height (wasted), and deficient in vitamins and minerals (micronutrient malnutrition). The malnutrition rate shows a declining rate from 60 percentages to 41 percentage from 1997 to 2011 [16], which still need to be slowing down. As infant mortality rate and child health are determinant of socio-economic development and quality of life [3], a greater focus is needed on child nutrition by developing suitable and appropriate policies and practices across Bangladesh.

Malnutrition depends on many socio-economic factors. Mothers are considered as the main catalyst in better health, nutrition, education, physical growth, and mental development of children. Higher level of mother's nutritional knowledge and practice reduce the child mortality rate because educated mother are able to provide concern about child's health and nutrition, exclusive breast feeding and Infant and Young Child Feeding (IYCF), food processing and preservation, their proper treatment during illness, information relating to vaccination, hygiene, water and sanitation etc. According to The World Bank (1993), mother's education is needed to improve child health status and lowering infant mortality rate [18]. Caldwell [4] concluded that children of educated mothers have better health condition than that of uneducated mothers. Glewwe [10] explained that health knowledge is significant factor which is able to explain the relationship between mother's education and child health. Maternal education can improve child health and reduce infant mortality through various ways like women empowerment, enhanced use of modern health care services, small family size, better health knowledge, and increased family income [1], [5]. Various studies showed that there is significant association between motherly learning and child health and use of health facilities than father education [14]. In the similar tone, Saaka [15] stated that maternal childcare knowledge index of mothers is strongly and positively associated with mean height-for-age Z-score (HAZ) of children and there is a great impact of socioeconomic and demographic status of maternal nutritional knowledge index and nutritional status of children. Geale [9] explained that there is a significant effect of maternal education on child health outcomes of a mother's male and female children by measuring both height-for-age and weight-for-height. Makoka [13] showed that maternal education plays an important role in addressing child malnutrition in Malawi, Tanzania, and Zimbabwe. Maternal education works through a number of pathway variables like- socioeconomic and demographic status, nutritional and health related knowledge and practice, health seeking and reproductive behavior that directly affect 
child health outcomes [6], [10]. In order to reduce mothers' knowledge and practice on nutrition and baby care are very crucial as they are caregivers to the child.

Poverty, low levels of education, lack of nutritional knowledge and practices and poor access of health services are the main reasons of malnutrition in Bangladesh. Edris [7] explained that children from low-income group are at high risk of being wasted, underweight and stunted than children of better income families. Low family income also increases the rate of infection through such mechanisms as inadequate personal and environmental hygiene [7]. Overpopulation is also alarming in Bangladesh though population growth rate is decreased substantially. So, unplanned socioeconomic and demographic situation leads to worst situation day by day and slum dwellers are the worst sufferer in this case. Though most slum dwellers uses pumped water for drinking but poor housing, overcrowding, together with the unhealthy environment due to poor sanitation, pollution and lack of systematic removal of garbage and solid waste and poor access to health care lead to high rates of child illness, malnutrition and food insecurity. So, slum people are exposed to greater risk of nutritional deficiency disease where young children are more vulnerable. Poor socioeconomic and demographic condition, poor feeding pattern, poverty and lack of proper nutritional knowledge are the prime causes for malnutrition in Bangladesh [12]. In the 1950s, the United Nations and its agencies became serious to reduce malnutrition and thus malnutrition became the study subject world widely [19].

Malnutrition has multifarious impacts. It increases the risk of maternal and child mortality, excess morbidity, premature delivery, elevated risks of heart disease and diabetes, reduced productivity, cognitive performance, and intellectual and learning capacity. Malnutrition and infection interact in a vicious cycle as the presence of one lead to the increase of other and is strongly correlated with social and economic inequalities. Malnutrition not only affects individuals, but its effects are also passed from one generation to the next as malnourished mothers give birth of a malnourished child. Nutritional deficiencies can lead to increase the rate of morbidity and mortality [2]. Acute malnutrition or wasting increase the rate of mortality where chronic malnutrition has a more insidious and long-standing impact on child health by depressing the immune function, increasing of infectious diseases and duration of illnesses which increase fatality rate. Stunting is the cause of growth retardation of babies and puts a negative impact on adult height. Again, malnutrition has a great negative impact on the proper functioning of the brain [11]. Mother's health and consciousness determines baby's health, long months before childbirth. Even after birth, mother's health and awareness determine child health. Thus, mother's nutritional knowledge and practice level identification are important as there is a great significance role of mother's nutritional knowledge and practice on their child health. The problem of malnutrition has a great negative impact on health, education, and the economy of our country.

Nutritional knowledge refers to an individual's understanding of nutrition, including the intellectual ability to remember and recall food and nutrition-related terminology, specific pieces of information and facts [8], where nutritional practice refers, observable actions of an individual that could affect his/her or others' nutrition, such as eating, feeding, washing hands, cooking and selecting foods [8]. Used thirty inventory items to determine nutritional knowledge levels, [20] assessed effects of mother's nutritional knowledge on attitudes and behaviors of children about nutrition. They divided knowledge level as low and high level. Food and Agriculture organization of the United Nations [8] described the procedure to measure the nutritional knowledge, attitude, and practice. In the manual, there are 13 modules named feeding infants ( $0-6$ months), feeding young children (6-23 months), diet of school-aged children, nutrition during pregnancy and lactation, undernutrition, iron-deficiency anemia, vitamin A deficiency, iodine deficiency, food safety, personal hygiene water and sanitation, food-based dietary guidelines, overweight and obesity [8]. To make better children's wellbeing in impoverished communities, it is necessary to provide more insight on impact of mother's nutritional knowledge and practices on child health outcomes.

\section{B. Objectives of the Study}

The research aims to measure mother's nutritional knowledge and practices level in the slum of Khulna city.

\section{RESEARCH METHODS}

\section{A. Study Area and Sample Size}

The study is carried out in four slums of Khulna city of Khulna district of Bangladesh. Mothers having children aged 2 to 5 years are selected as respondents. Mothers who are severely sick or not-caregiver are not included in the survey. A number of 80 mothers are surveyed using structured questionnaire in 2015 .

\section{B. Variable Specification}

\section{Nutrition-related knowledge and its score}

We follow Food and Agriculture Organization (FAO) of the United Nations' guidelines to measure mother's nutrition-related knowledge and practice. FAO [8] prepares manual for assessing nutritional related knowledge, attitudes, and practices and mentions 13 most common nutrition issues. The issues are as follows: feeding infants younger than 6 months, feeding young children (6-23 months), diet of school-aged children, nutrition during pregnancy and lactation, under nutrition, iron-deficiency anaemia, vitamin A deficiency, iodine deficiency, food safety, personal hygiene, water and sanitation, food-based dietary guidelines, overweight and obesity. Based on FAO KAP manual on nutrition, we customize and consider 13 common and important issues for assessing mothers' knowledge on nutrition [8]. The issues covers pregnancy period, delivery period, lactation period, breast feeding till first 6 months, IYCF, immunization, Oral Rehydration Solution (ORS), vitamin and mineral deficiency disorders, personal hygiene, water and sanitation, food safety, food based knowledge, and treatment behavior. Among identified 13 issues, the research considers 38 sub-questions with four options in each. Option A of each question is the most 
relevant (correct) answer where D is the most deviated (irrelevant/ incorrect) answer. Each question is answered from 1 to 4 where 'answer A' is scored 4 and 'answer D' is scored 1. Thus, the maximum knowledge score (all correct answers) of 38 questions are 152, and the minimum score (all wrong answers) is 38. The knowledge score 130 and above is categorized as high level knowledge score, 120129 as medium level, and $<120$ as low level knowledge score.

\section{Nutrition-related practices and its score}

The research intends to check how far mothers in the slum area practice or apply nutrition related issues in their practical life. The research investigates the practice level of the mother/family on the identified 13 important and common issues (as mentioned in the knowledge section) affecting baby's nutrition. In this case, the research also considers 38 questions with five options in 34 questions. Option A of each question is the most relevant (best practice) and is scored 5, where option $\mathrm{E}$ is the most deviated (irrelevant/ incorrect) practice and is scored 1. For the rest 4 , each question is answered between ' $A$ ' and ' $B$ ', where option $\mathrm{A}$ of each question is more relevant (best practice) and is scored 2,where option B is more deviated (irrelevant/ incorrect) practice and is scored 1. Thus, the maximum knowledge score (all correct answers) of 38 questions are 178, and the minimum knowledge score (all wrong answers) of 38 questions are 38 . The nutrition related practice score 140 and above is categorized as high practice score, 131-139 as medium practice score, and below 131 as low practice score.

\section{Hypothesis Testing}

The research performs hypotheses testing to observe mean differences of nutritional related practice score across sub-groups, i.e., child's gender, mother's education level and family income level.

\section{Regression Analysis}

A linear regression model is developed to identify factors influencing nutrition related practice score in the family.

NPS $=\beta_{0}+\beta_{1}$ MEdu $+\beta_{2}$ Male $+\beta_{3}$ Mage $+\beta_{4}$ FInc + $\beta_{5}$ NKS $+\beta_{6}$ Fchild $+\beta_{7}$ MEmploy $+\beta_{8}$ House $+u_{i}$

Here, $N P S=$ Nutritional practice score, $M E d u=$ mother's education; Male $=$ gender of the child (dummy variable: $1=$ male; $0=$ otherwise); Mage $=$ mother's age; FInc $=$ Family income ('000BDT); NKS = Nutritional knowledge score; Fchild = First child (dummy variable: 1= yes; 0=otherwise); MEmploy = Mother's employment status (dummy variable: $1=$ employed; $0=$ otherwise); House = house ownership (dummy variable: $1=$ own house; $0=$ otherwise); $u=$ error term.

\section{RESULTS AND DISCUSSIONS}

The research focuses on socio-economic profile of the respondents and their families, nutritional knowledge and practice level of the surveyed mothers and families and factors influencing nutritional practice score.

\section{A. Socio-Economic Profile of the Respondents and Their} Families

1. Mothers' age and education

Surveyed mothers are relatively young aged. Table 1 represents that largest portion of the slum mothers (56.39 percent) are between 19 and 25 years, where the mean age is 25.90 .

TABLE 1: AGE DISTRIBUTION OF MOTHERS

\begin{tabular}{ccc}
\multicolumn{4}{c}{ TABLE 1: AGE DISTRIBUTION OF MOTHERS } \\
\hline Age Range & Frequency & Percentage \\
\hline 16 to 18 & 2 & 2.5 \\
19 to 25 & 45 & 56.3 \\
26 to 32 & 26 & 32.5 \\
33 years and above & 7 & 8.8 \\
\cline { 2 - 3 } Total & 80 & 100.0 \\
\cline { 2 - 3 } & &
\end{tabular}

Regarding mother's education, surveyed data also shows that 15 percent mothers are illiterate and 32.5 percent mothers completed primary level education. About half of the surveyed mother reached in the secondary level but about only 1 percent of total passed secondary level.

\section{Employment status and family income}

The mother's employment status of the slum area is shown in the following figure. The employment rate is high (50 percent) in Bil Slum among the four selected slums. The employment rate for Mohi's slum, Pora slum and Rupsha slums are 35 percent, 45 percent and 40 percent respectively. Survey experience goes that most employed mothers are engaged in the informal jobs near their houses.

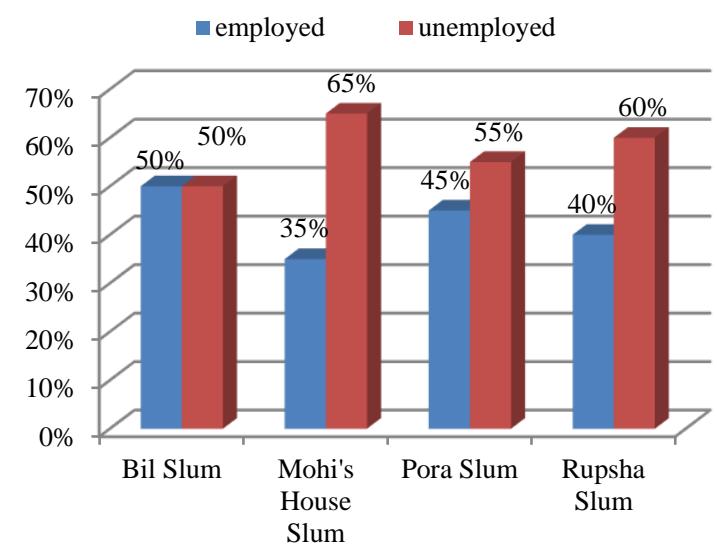

Fig. 1. Employment status of the mothers across slums Source: Field survey.

The monthly family income includes both incomes of the mother (if employed) and of other family member(s). The average per capita monthly income is BDT 7,900 (US\$1 = BDT83, approximately), where minimum monthly income is BDT 3,000 and maximum is BDT 15,000. The average figure is not big enough to ensure food, cloth, education, and other requirements of the family.

\section{House ownership}

Among surveyed households, 46.25 percent family live in their own house and accordingly 53.75 percent live in the rented house. Rented households do not consider handsome investment in toilet, kitchen, ventilation etc. as they might move to other places shortly. 


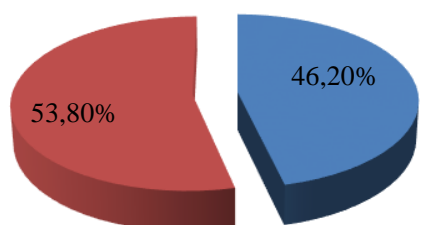

$\square$ Own $\square$ Rented

Fig. 2. House ownership.

\section{Utility possession}

Survey result shows that all households have access to safe drinking water and electricity facility, where 40 percent households enjoy separate kitchen facility, 63.75 percent households enjoy ventilation facility (having window) at home, 83.75 percent $\mathrm{HHs}$ enjoy toilet facility, and 67.5 percent households own television. During data collection we observe that most of the accommodation in slum is mostly a house with 5 to 6 rooms, with one toilet and one kitchen, where each family resides in a room and share the single toilet and kitchen with other residents.

TABLE 2: SLUM-WISE HOUSEHOLD'S UTILITY STATUS

\begin{tabular}{|c|c|c|c|c|c|c|}
\hline \multirow[b]{2}{*}{ Particulars } & \multirow{2}{*}{$\begin{array}{c}\mathrm{HH} \\
\& \\
\%\end{array}$} & \multicolumn{4}{|c|}{ Area name } & \multirow[b]{2}{*}{ Total } \\
\hline & & $\begin{array}{c}\text { Bil } \\
\text { Slum }\end{array}$ & $\begin{array}{l}\text { Mohi's } \\
\text { Slum }\end{array}$ & $\begin{array}{l}\text { Pora } \\
\text { Slum }\end{array}$ & $\begin{array}{l}\text { Rupsha } \\
\text { Slum }\end{array}$ & \\
\hline Having safe & $\mathrm{HH}$ & 20 & 20 & 20 & 20 & 80 \\
\hline drinking water & $\%$ & 100.0 & 100.0 & 100.0 & 100.0 & 100.0 \\
\hline Having kitchen & $\mathrm{HH}$ & 9 & 8 & 6 & 9 & 32 \\
\hline facility & $\%$ & 45.0 & 40.0 & 30.0 & 45.0 & 40.0 \\
\hline \multirow{2}{*}{$\begin{array}{l}\text { Having ventilation } \\
\text { facility }\end{array}$} & $\mathrm{HH}$ & 12 & 11 & 16 & 12 & 51 \\
\hline & $\%$ & 60.0 & 55.0 & 80.0 & 60.0 & 63.75 \\
\hline \multirow{2}{*}{$\begin{array}{l}\text { Having toilet } \\
\text { facility }\end{array}$} & $\mathrm{HH}$ & 16 & 18 & 19 & 14 & 67 \\
\hline & $\%$ & 80.0 & 90.0 & 95.0 & 70.0 & 83.75 \\
\hline \multirow{2}{*}{ Having electricity } & $\mathrm{HH}$ & 20 & 20 & 20 & 20 & 80 \\
\hline & $\%$ & 100.0 & 100.0 & 100.0 & 100.0 & 100.0 \\
\hline \multirow{2}{*}{ Owning television } & $\mathrm{HH}$ & 13 & 12 & 16 & 13 & 54 \\
\hline & $\%$ & 65.0 & 60.0 & 80.0 & 65.0 & 67.5 \\
\hline
\end{tabular}

\section{Maternal nutritional knowledge}

The table below shows mother's knowledge level on 13 identified categories. Results show that 43.75 percent mothers have higher level knowledge on pregnancy period, where 48.75 percent have moderate level and 7.50 percent have lower level knowledge on the issue. Though the study covers mothers of slum areas, still they acquire some knowledge on pregnancy related issues which are related to baby's nutrition. Results also show that respondents have full knowledge on water \& sanitation, and food safety related issues. At least 90 percent mothers possessed higher level knowledge on delivery period, lactation period, immunization, Oral Rehydration Solution (ORS), personal hygiene, and treatment behavior issues. Mothers have very low-level knowledge on vitamin and mineral deficiency disorder ( 93.75 percent respondents), food based issues ( 80 percent respondents), breast feeding period (58.75 percent respondents). Considering the overall knowledge level, results show that only 28.75 percent mothers possess higher level knowledge, where 52.5 percent have moderate level knowledge, and 18.75 mothers have lower level knowledge on nutrition related issues. Various government programs, community clinics, and NGOs have implemented programs in the city area through which even mothers in the slum area have acquired some basic knowledge on nutrition. Television also telecasts various programs on nutrition as well. Still only 28.75 percent mothers possessed high level knowledge on nutrition which needs to be increased for the betterment of the baby's health. As mothers are the main caregivers, their knowledge is crucial for baby's health and nutritional. In fact, when these mothers become old, their perception matter in their grandchild's health also. In the combined and interconnected family culture of Bangladesh, the old especially female exerts influence on various important decisions related to mother and baby. As they mostly reside at home, they pass the highest time with the pregnant mothers and newborn babies.

\begin{tabular}{cccc}
\multicolumn{4}{c}{ TABLE 3: MOTHER'S NUTRITION RELATED KNOWLEDGE LEVEL } \\
\hline Issues of mother's & $\begin{array}{c}\text { Higher } \\
\text { level }(\%)\end{array}$ & $\begin{array}{c}\text { Moderate } \\
\text { level }(\%)\end{array}$ & $\begin{array}{c}\text { Lower } \\
\text { level }(\%)\end{array}$ \\
nutritional knowledge & 43.75 & 48.75 & 7.50 \\
Pregnancy period & 97.5 & 1.25 & 1.25 \\
Delivery period & 92.5 & 1.25 & 6.25 \\
Lactation period & 12.5 & 28.75 & 58.75 \\
Breast feeding period & 26.25 & 57.50 & 16.25 \\
Infant and Young Child & 97.50 & 0 & 2.50 \\
Feeding (IYCF) & 95.00 & 0 & 5.00 \\
Immunization & 1.25 & 5.00 & 93.75 \\
Oral Rehydration Solution & & & 1.25 \\
(ORS) & 98.75 & 3.75 & 0 \\
Vitamin and mineral & 100 & 0 & 0 \\
deficiency disorder & 100 & 0 & 80.00 \\
Personal hygiene & 0 & 20.00 & 5.00 \\
Water and sanitation & 90.00 & 5.00 & 18.75 \\
Food safety & 28.75 & 52.50 & \\
Food based knowledge & &
\end{tabular}

Source: Field survey.

\section{Maternal nutritional-related practice level}

The table below shows extent in which mothers practiced nutritional related issues in their life. We notice that highest percentage of mothers (46.25 percent) have lower level nutritional related practice in their family and life, where the least percentage of mothers (11.25 percent) practice higher level nutritional related issues in their practical life.

TABLE 4: MOTHER'S NUTRITION RELATED PRACTICE LEVEL

\begin{tabular}{cc}
\hline Practice level & Percentage \\
\hline Lower level & 46.25 \\
Moderate level & 42.50 \\
Higher level & 11.25 \\
\hline Total & 100.00 \\
\hline
\end{tabular}

Source: Field survey.

It is very alarming that only about one-tenth mothers apply higher level nutrition related issues. Slum people are relatively disadvantaged in economic aspects. The average family income of the surveyed families is BDT 7,900 (US\$ 95.18 approximately, considering US\$1 = BDT83). In this case, each family has 1.85 children on average, where every family had at least one child. Nutritional practice much depends on income of the households. In this case, household's average income is very low to afford nutrient food and medical facilities etc. According to the World Bank If anybody lives less than $\$ 1.90$ per day is categorized as extremely poor [17]. Even considering 3.85 as average family size, average income per member is US\$0.82, which 
is by far less than threshold of per day living expenditure of extremely poor. Surveyed mothers also lack nutrition related knowledge. We recall that only 28.75 percent mothers possess high level nutrition related knowledge. With poor nutritional knowledge, it is difficult to maintain high practice level.

7. Relation between maternal nutritional related knowledge and practice

TABLE 5: RELATION BETWEEN MATERNAL NUTRITIONAL RELATED KNOWLEDGE AND PRACTICE

\begin{tabular}{ccccc}
\hline \multirow{5}{*}{$\begin{array}{c}\text { Knowledge } \\
\text { level }\end{array}$} & $\begin{array}{c}\text { Lower } \\
\text { level }\end{array}$ & $\begin{array}{c}\text { Moderate } \\
\text { level }\end{array}$ & $\begin{array}{c}\text { Higher } \\
\text { level }\end{array}$ & Total \\
\cline { 2 - 5 } Lower level & 80.00 & 20.00 & 0.00 & 100.00 \\
Moderate & $(15.00)$ & $(3.75)$ & $(0.00)$ & $(18.75)$ \\
level & 54.76 & 42.86 & 2.38 & 100.00 \\
& $(28.75)$ & $(22.50)$ & $(1.25)$ & $(52.50)$ \\
Higher level & 8.70 & 56.52 & 34.78 & 100.00 \\
& $(2.50)$ & $(16.25)$ & $(10.00)$ & $(28.75)$ \\
Total & 46.25 & 42.50 & 11.25 & 100.00 \\
& Pearson & chi2 $2(4)=30.16$, & \\
Pr=0.000; Fisher's exact $=$ & 0.000 &
\end{tabular}

N.B.: percent in the parenthesis indicate cell percent.

We notice that 80 percent mothers with low level of nutritional knowledge also practice low level of nutritional issue, where 20 percent exercise medium level nutritional issue in their family/ life. Surprisingly, none of them exercise high level of practice. It hints that mothers with low level of knowledge have less likelihood of maintaining nutritional issues at the higher level. Since many of them possess less knowledge, they might not perceive importance of nutritional issues to be maintained for the children. However, having higher knowledge on nutrition neither guarantee that they will apply those in their daily life. We notice that those who had higher level knowledge, about one-third (34.78 percent) of them implemented higher level practice in their life. The rest maintained either medium level or low level practice. Actually, they are absolutely poor and cannot afford food and treatments. Moreover, many mothers in the slums are engaged in different informal activities and remain out of the family for long hours for making money. Therefore, apart from poverty, many working mothers cannot maintain nutritional issues for their babies.

\section{Nutritional related practice across groups}

This section compares nutritional related practice scores across gender, across mother's education and across family income. When the current baby is a girl, mothers' average of nutritional practice score is 131.74, where the score is 130.24 when the current baby is a boy. The t-test result shows that there is no statistically significant difference between genders of baby. Though the average score for both types of children are poor, still we do not notice any discrimination in treatments between male and female children which is nice for developing countries. In the traditional family culture, male is the source of livelihood options of the parents for which many people in the past expected male children and treated better to the male child.
TABLE 6: RESULT OF HYPOTHESIS TESTING

\begin{tabular}{|c|c|c|c|c|c|}
\hline Issue & Groups & Obs & Mean & Std. Err. & Statistics \\
\hline \multirow{3}{*}{$\begin{array}{l}\text { Gender of } \\
\text { child }\end{array}$} & Male & 43 & 131.74 & 1.1897 & \multirow{3}{*}{$t=0.7675$} \\
\hline & Female & 37 & 130.24 & 1.5922 & \\
\hline & Diff. & & 1.50 & 1.9556 & \\
\hline \multirow{3}{*}{$\begin{array}{l}\text { Mother's } \\
\text { education }\end{array}$} & $\begin{array}{l}\text { Up to } \\
\text { primary }\end{array}$ & 38 & 129.71 & 1.5361 & \multirow{3}{*}{$t=-1.3161 *$} \\
\hline & $\begin{array}{l}\text { Above } \\
\text { primary }\end{array}$ & 42 & 132.26 & 1.2121 & \\
\hline & Diff. & & -2.55 & 1.9385 & \\
\hline \multirow{3}{*}{$\begin{array}{l}\text { Monthly } \\
\text { family } \\
\text { income }\end{array}$} & $\begin{array}{c}\text { Up to BD } \\
10 \mathrm{~K}\end{array}$ & 54 & 129.87 & 1.1643 & \multirow{3}{*}{$t=1.7715^{* *}$} \\
\hline & $\begin{array}{c}10 \mathrm{~K} \text { and } \\
\text { above }\end{array}$ & 26 & 133.50 & 1.6945 & \\
\hline & Diff. & & -3.63 & 2.0489 & \\
\hline
\end{tabular}

Source: Field survey.

Mothers who attained higher education than primary level have significantly higher nutritional related practice score than mothers whose education level was confined up to primary level. Higher educated (higher than primary level) mother's nutrition related practice in the family are 2.55 points more than that of lower educated (up to primary level) mothers which is statistically significant at the 0.10 level. Monthly family income also exerted effect in the same manner. Families whose monthly income is more than BDT 10,000 (ten thousand) has 3.63 points more nutritional related practice than families whose monthly family incomes are less than BDT 10,000. The finding is statistically significant at the 0.05 level. Maintaining nutritional related issues in the family require availing some goods and services for the mother and children which require money. Therefore, higher income families are able to manage those and thus their score are higher than that of lower income households.

TABLE 7: ESTIMATED RESULT OF LINEAR REGRESSION

\begin{tabular}{|c|c|c|}
\hline Variables & Coefficient & $\begin{array}{c}\text { Standard } \\
\text { error }\end{array}$ \\
\hline Mother's education & -0.1781 & 0.2761 \\
\hline $\begin{array}{l}\text { Gender of youngest child (D: } 1= \\
\text { male; } 0=\text { female) }\end{array}$ & $0-.3985$ & 1.5625 \\
\hline Age of the mother & 0.1979 & 0.2370 \\
\hline Monthly family income ('000 BDT) & $0.8582 * *$ & 0.3095 \\
\hline Nutritional related knowledge & $0.7974 * * *$ & 0.1171 \\
\hline $\begin{array}{l}\text { First child in the family (D: } 1=\text { yes; } \\
\qquad 0=\text { otherwise) }\end{array}$ & $-5.6783 * *$ & 2.2664 \\
\hline $\begin{array}{l}\text { Mother's employment }(\mathrm{D}: 1= \\
\text { employed; } 0=\text { otherwise })\end{array}$ & -1.6950 & 1.5011 \\
\hline $\begin{array}{l}\text { House ownership (dummy: } 1=\text { own; } \\
\qquad 0=\text { otherwise) }\end{array}$ & 31.1716 & 15.9548 \\
\hline
\end{tabular}

Regression result shows that other factors remaining the same, with an increase in monthly family income by one thousand (BDT), nutritional practice score increased by about 0.86 unit which is statistically significant at the 0.05 level. Higher income helps to purchase food and other essential goods and services which help to develop mother's as well as baby's health and nutrition. Other things remaining constant, when mother's nutritional knowledge is increased by 1 unit, nutritional related practice in the family also increased by about 0.80 unit, which is statistically significant at the 0.01 level. Better knowledge can dictate actual decision making in the family with regard to food, nutrition, hygiene and health related issues. Mothers with first child have less application of nutritional related issues in the family than mothers with more than one child. Result 
shows that more than one-child mother practiced nutrition related issues by 5.68 points more than that of first/one-child mother. Mother with more than one child is more experienced. Mother and the family gain more experience on health and nutritional related issues from earlier child (children). A family (mother) tries to improve at least the bad experiences in their earlier stages of life. It hints the essence of providing more training on the potentially new mothers about maternal and child health related issues.

\section{RECOMMENDATION AND CONCLUSION}

Less than one-third mothers have high level knowledge on the nutrition related issues. As mothers are the caregivers to themselves and to children, their knowledge is to be improved. As slum people are underprivileged in many respects, authority need to design special campaign in the slum areas. As mothers with more than one-child, had higher application of nutritional issues in the family than single or first-child mother, it indicated that they applied their experiences and learning in the subsequent periods. Thus, the research suggests one to one special counseling for potential new mothers in the slum area. Government community clinics can focus on slum areas with increased manpower if required. Trained mothers will be able to maintain those in the subsequent period of their lives. Nutritional related application in the family is even worse than knowledge level. Only 11.25 percent mothers apply higher level nutritional related issues in the family which is a serious threat for mother and child health. Moreover, mothers with higher level knowledge even could not implement those in the family. Only about one-third mothers with higher level knowledge had higher level nutritional related practice in their life. Poor application despite higher level knowledge is a clear indication of economic poverty. Pregnant mothers in Bangladesh have option of getting some free medical consultation from government hospitals and some free (selective) medicine, but their poverty resists them to manage food and other health services. Thus, government might have some logistic support to the pregnant mothers of economically disadvantaged families. Empirical findings of the study also showed that higher income increased application of nutritional related issues in the family. It might be noticed that Bangladesh government provide regular incentives (rice, cash etc.) to the poor, old and widows (of poor class). In the same manner, the research advocates for providing some supports for the pregnant mothers and newborn babies in the slum areas. Specific supports required for the baby like baby foods, and specific supports for the pregnant mothers (like transportation cost for pregnant mothers) might bring higher effect on maternal and child health. Bangladesh has attained a huge success in reducing child mortality, mass immunization, and in several other health issues. However, very specific communities like slum dwellers still need special attention for development of the country.

\section{REFERENCES}

[1] Anwar, S. and Nasreen, S. (2013). Maternal Education and Child Nutritional Status in Bangladesh: Evidence from Demographic and Health Survey Data. Pakistan Journal of Life and Social Sciences, 11(1),77-84.

[2] Bauer, B. (2002). Nutritional Assessment of Children Enrolled in a Structured Childcare Setting, Unpublished Masters Thesis, Food and Nutrition sciences, The Graduate College, University of WisconsinStout, Menomonie, WI 54751.

[3] BDHS (2014). Bangladesh Demographic and Health Survey 2014 Bangladesh Demographic and Health Survey (BDHS), National Institute of Population Research and Training. Ministry of Health and Family Welfare, Dhaka, Bangladesh, 33-42.

[4] Caldwell, J.C. (1994). How is Greater Maternal Education Translated into Child Health? Health Transition Review, 4,224-229.

[5] Castro, M.T. and Juarez, F. (1995). The Impact of Women's Education on Fertility in Latin America: Searching for Explanations. International Family Planning Perspectives, 21, 52-80.

[6] Desai, S. and Alva, S. (1998). Maternal Education and Child Health Is There a Strong Causal Relationship? Demography, 35(1), 71-81.

[7] Edris, M. (2007). Assessment of Nutritional Status of Preschool Children of Gumbrit, North West Ethiopia. Ethiopia Journal Health and Development, 21(2), 125-129.

[8] FAO (2014). Guidelines for Assessing Nutrition-related Knowledge, Attitudes and Practices, Food and Agriculture Organization of the United Nations, Rome, 8-18.

[9] Geale, K. (2001). The Effects of Mothers' Education on Nutritional Outcomes of Their Children in Nicaragua. Department of Economics, College of Management and Economics. Nicaragua.

[10] Glewwe, P, (1999). Why Does Mother's Schooling Raise Child Health in Developing Countries? Evidence from Morocco. The Journal of Human Resources, 34(1), 124-159.

[11] GOI and UNICEF (1999). Nutritional Survey of Children under Two Attending Routine Immunization Sessions at Primary Health Care Centers in Iraq. The Ministry of Health (GOI) and UNICEF/Iraq, Iraq.

[12] Hossain, A. (2012). Comparative Study on Nutritional Status of Children (aged 6 to 24 months) and Their Mothers between Selected Slum and Non Slum Areas of Dhaka City. Unpublished Masters Thesis, Economics Discipline, Dhaka University, Dhaka.

[13] Makoka, D. (2013). The Impact of Maternal Education on Child Nutrition: Evidence from Malawi, Tanzania, and Zimbabwe. Demographic and Health Survey, the United States Agency for International Development. ICF International Calverton, WP84, Maryland.

[14] Mondal, M. N.I., Hossain, K. and Ali, K. (2009). Factors Influencing Infant and Child Mortality: A Case Study of Rajshahi District, Bangladesh. Journal of Human Ecology, 26 (1), 31-39.

[15] Saaka, M. (2014). Relationship between Mothers' Nutritional Knowledge in Childcare Practices and the Growth of the Children Living in Improvised Rural Communities. International Centre for Diarrhoeal Disease Research, Bangladesh, 32(2), 237-248.

[16] Save the children (2015). Malnutrition in Bangladesh: Harnessing Social Protection for the Most Vulnerable. Save the Children Report, London.

[17] The World Bank. (2020). Poverty. Retrieved June 20, 2020, from https://www.worldbank.org/en/topic/poverty/overview.

[18] The World Bank (1993). World Development Report 1993: Investing in Health. Oxford University Press, New York.

[19] WHO (1996). Why Have Mortality Rates for Severe Malnutrition Remained So High? Bulletin of the World health Organization, 74(2), 223-229.

[20] Yabanci, N., Kisac, I. and Karakus, S.S. (2013). The Effects of Mother's Nutritional Knowledge on Attitudes and Behaviors of Children about Nutrition. 5th World Conference on Educational Sciences - WCES 2013, Ankara University, Faculty of Health Sciences, Department of Nutrition and Dietetics, Ankara, 06340, Turkey. 